\title{
Galangin Attenuates Liver Injury, Oxidative Stress and Inflammation, and Upregulates Nrf2/HO-1 Signaling in Streptozotocin-Induced Diabetic Rats
}

\author{
Wesam Al-Amarat ${ }^{1}$, Mohammad H. Abukhali1 ${ }^{2,3}{ }^{\oplus}$, Osama Y. Althunibat ${ }^{3} \mathbb{D}$, Manal A. Alfwuaires ${ }^{4}$, \\ Mashael M. Alnamshan ${ }^{5}$ D, Amany I. Alqosaibi ${ }^{5}$, Ahmad F. Ahmeda ${ }^{6,7}$, Emadeldin M. Kamel ${ }^{8}$, Hany H. Arab ${ }^{9}$ \\ and Ayman M. Mahmoud 10,*(D)
}

check for updates

Citation: Al-Amarat, W.; Abukhalil, M.H.; Althunibat, O.Y.; Alfwuaires, M.A.; Alnamshan, M.M.; Alqosaibi, A.I.; Ahmeda, A.F.; Kamel, E.M.; Arab, H.H.; Mahmoud, A.M. Galangin Attenuates Liver Injury, Oxidative Stress and Inflammation, and Upregulates Nrf2/HO-1 Signaling in Streptozotocin-Induced Diabetic Rats. Processes 2021, 9, 1562. https://doi.org/10.3390/pr9091562

Academic Editor: Dionysios

V. Chartoumpekis

Received: 13 July 2021

Accepted: 30 August 2021

Published: 1 September 2021

Publisher's Note: MDPI stays neutral with regard to jurisdictional claims in published maps and institutional affiliations.

Copyright: (c) 2021 by the authors. Licensee MDPI, Basel, Switzerland. This article is an open access article distributed under the terms and conditions of the Creative Commons Attribution (CC BY) license (https:/ / creativecommons.org/licenses/by/ $4.0 /)$.
1 Department of Medical Support, Al-Karak University College, Al-Balqa' Applied University, Salt 19117, Jordan; wsam.amarat@bau.edu.jo

2 Department of Biology, College of Science, Al-Hussein Bin Talal University, Ma'an 71111, Jordan; mabukhalil@ahu.edu.jo

3 Department of Medical Analysis, Princess Aisha Bint Al-Hussein College of Nursing and Health Sciences, Al-Hussein Bin Talal University, Ma'an 71111, Jordan; Osama.y.althunibat@ahu.edu.jo

4 Department of Biological Sciences, Faculty of Science, King Faisal University, Al-Ahsa 31982, Saudi Arabia; malfwuaires@kfu.edu.sa

5 Department of Biology, College of Science, Imam Abdulrahman Bin Faisal University, Dammam 31441, Saudi Arabia; malnamshan@iau.edu.sa (M.M.A.); amgosaibi@iau.edu.sa (A.I.A.)

6 Department of Basic Medical Sciences, College of Medicine, Ajman University, Ajman 346, United Arab Emirates; a.ahmeda@ajman.ac.ae

7 Center of Medical and Bio-allied Health Sciences Research, Ajman University, Ajman 346, United Arab Emirates

8 Chemistry Department, Faculty of Science, Beni-Suef University, Beni-Suef 62514, Egypt; emad.abdelhameed@science.bsu.edu.eg

9 Department of Pharmacology and Toxicology, College of Pharmacy, Taif University, Taif 21944, Saudi Arabia; h.arab@tu.edu.sa

10 Physiology Division, Zoology Department, Faculty of Science, Beni-Suef University, Beni-Suef 62514, Egypt

* Correspondence: ayman.mahmoud@science.bsu.edu.eg

Abstract: Chronic hyperglycemia increases the risk of liver damage. Oxidative stress and aberrant inflammatory response are entangled in diabetes-associated liver injury. This study evaluated the protective effect of the flavonoid galangin (Gal) on glucose intolerance, liver injury, oxidative stress, inflammatory response, and Nrf2/HO-1 signaling in diabetic rats. Diabetes was induced by streptozotocin (STZ), and the rats received Gal for six weeks. STZ-induced rats showed glucose intolerance, hypoinsulinemia, elevated glycated hemoglobin (HbA1c), and decreased liver glycogen. Gal ameliorated glucose intolerance, reduced $\mathrm{HbA} 1 \mathrm{c} \%$, increased serum insulin and liver glycogen and hexokinase activity, and suppressed glycogen phosphorylase, glucose-6-phosphatase and fructose1,6-biphosphatase in diabetic rats. Circulating transaminases, ALP and LDH, and liver ROS, MDA, TNF- $\alpha$, IL-1 $\beta$, and IL- 6 were increased and GSH, SOD, and CAT were diminished in diabetic rats. In addition, diabetic rats exhibited multiple histopathological alterations and marked collagen deposition. Treatment with Gal mitigated liver injury, prevented histopathological alterations, decreased ROS, MDA, pro-inflammatory cytokines, Bax and caspase-3, and enhanced cellular antioxidants and Bcl-2. Gal downregulated hepatic Keap1 in diabetic rats and upregulated Nrf2 and HO-1 mRNA as well as HO-1 activity. Molecular modeling studies revealed the ability of Gal to bind to and inhibit NF- $\mathrm{BB}$ and Keap1, and also showed its binding pattern with HO-1. In conclusion, Gal ameliorates hyperglycemia, glucose intolerance, oxidative stress, inflammation, and apoptosis in diabetic rats. Gal improved carbohydrate metabolizing enzymes and upregulated Nrf2/HO-1 signaling.

Keywords: diabetes; flavonoids; Nrf2; oxidative stress; liver injury; hyperglycemia 


\section{Introduction}

Diabetes mellitus (DM) is a worldwide metabolic disorder characterized by persistent hyperglycemia leading to progressive damage of various internal tissues, including the liver [1]. Patients with DM are at a high risk of liver impairments, including abnormal liver enzymes, nonalcoholic fatty liver disease (NAFLD), cirrhosis, hepatocellular carcinoma, and acute liver failure [2]. The underlying mechanism of hyperglycemia-mediated liver injury includes the combination of increased oxidative damage and an aberrant inflammatory response [3]. Oxidative stress causes damage of cellular macromolecules, including biological membrane lipids, nucleic acids, and cellular proteins, resulting in cell injury and death [3]. In addition, excess reactive oxygen species (ROS) is implicated in stimulating inflammatory process, aggravating tissue damage and organs dysfunction. Indeed, the liver is an internal organ that plays a key role in the main metabolic pathways. It is involved in blood glucose homeostasis by balancing the uptake and storage of glucose via glycogenesis and its release through glycogenolysis and gluconeogenesis [4]. Defects in carbohydrate metabolizing machinery in addition to prevalent oxidative stress in DM result in various degrees of hepatocyte damage assigned by excess glycogen deposition, biomolecules oxidation; prominently lipid peroxidation (LPO); enhanced hepatocyte apoptosis, and stimulation of inflammatory process, which is furthered by necrosis, fibrosis, cirrhosis, and liver failure $[5,6]$. In this context, a previous clinical study found that the prevalence of severe liver fibrosis was $15.5 \%$ among the hospitalized patients with type 1 DM [7]. Therefore, therapeutic approaches aiming at ameliorating the imbalance in carbohydrate metabolism and attenuating antioxidant defenses can protect against diabetes-mediated liver injury.

The cells developed several defense mechanisms that serve to mitigate the cellular damages and prevent several diseases. The nuclear factor (erythroid-derived 2)-like 2 (Nrf2) has been emerged among the potential druggable targets to treat and prevent the progression of several diseases $[8,9]$. It elicits the expression of the antioxidant and cytoprotective genes [8]. In its inactive state, Nrf2 is sequestered in the cytosol by Keap1 in a complex disrupted upon exposure to ROS or electrophilic stress, leading to Nrf2 dissociation and subsequent nuclear translocation where it binds the antioxidant response element (ARE) and stimulate the transcription of antioxidant genes, such as, heme oxygenase (HO)-1, superoxide dismutase (SOD), and catalase (CAT) [8]. Activation of Nrf2 by a wide range of natural compounds protected against liver injury through attenuation of oxidative stress and fibrosis in rodents [10-13]. On the contrary, the lack of Nrf2 accelerated the progression of nutritional steatohepatitis and resulted in increased hepatic inflammation and fibrosis in mice fed methionine-and choline-deficient diet [14]. Therefore, Nrf2 activation could be a promising therapeutic approach for preventing or treating liver diseases.

Multiple studies have demonstrated that natural compounds have gained thoughtfulness as therapeutic candidates for prevention and treatment of diabetes and its complications $[15,16]$. Galangin (Gal), an active flavonoid present in honey and the roots of Alpinia officinarum, possesses numerous potential therapeutic effects, including antioxidant, anti-inflammatory and hepatoprotective properties $[10,17,18]$. Gal exhibited potential anti-hyperglycemic and anti-dyslipidemia effects in diabetic rats $[19,20]$. In addition, $\mathrm{Gal}$ is a potential dipeptidyl peptidase-4 (DPP-4) inhibitor that enhances insulin activity and glucose uptake in skeletal muscle [21]. Gal attenuated hyperglycemia-induced cardiomyopathy in type 1 diabetic rats by reducing oxidative damage and suppressing inflammation and apoptosis [18]. Furthermore, Gal exhibited hepatoprotective effects against cyclophosphamide (CP) toxicity by preventing oxidative injury, inflammation, and hepatic cell apoptosis [10]. Although multiple therapeutic effects of Gal have been demonstrated, its ameliorative effects on liver injury and carbohydrate metabolizing enzymes are yet to be investigated. This study evaluated the hepatoprotective effect of Gal in diabetic rats emphasizing on its antioxidant and anti-inflammatory actions and its modulatory effects on the key enzymes of carbohydrate metabolism. 


\section{Materials and Methods}

\subsection{Animals and Experiment Design}

Male Wistar rats (180 $\pm 10 \mathrm{~g})$ were housed under standard conditions of humidity and temperature on a $12 \mathrm{~h}$ light/dark cycle and supplied food and water ad libitum.

Streptozotocin (STZ, Sigma, St. Louis, MO, USA) was in $0.1 \mathrm{M}$ citrate buffer (pH 4.5) and $50 \mathrm{mg} / \mathrm{kg}$ was injected intraperitoneally (i.p.) to induce type I DM [22,23]. In parallel, normal rats received citrate buffer. After $72 \mathrm{~h}$, rats with fasting blood glucose $\geq 250 \mathrm{mg} / \mathrm{dL}$, measured by Roche Diagnostics glucometer (Mannheim, Germany), were selected for further investigation.

A total of 24 rats (12 normal and 12 diabetic) were divided into four groups $(n=6)$ as follows:

Group I (Control): normal rats received the vehicle.

Group II (Gal): normal rats received $15 \mathrm{mg} / \mathrm{kg}$ body Gal [10].

Group II (Diabetic): diabetic rats received the vehicle.

Group IV (Gal): diabetic rats received $15 \mathrm{mg} / \mathrm{kg}$ body Gal [10].

Gal was purchased from Sigma Aldrich (St. Louis, MO, USA) and dissolved in 0.5\% carboxymethyl cellulose (CMC) and supplemented via oral gavage for six weeks. After the treatment period, the animals were anesthetized by ketamine/xylazine and blood was collected via cardiac puncture in plain and EDTA vacutainer tubes. Immediately, the animals were euthanized, and the liver was excised, washed with ice-cold $0.9 \%$ saline, blotted, and weighed. Portions of liver were fixed in 10\% neutral buffered formalin (NBF), and other portions were homogenized in $10 \mathrm{mM}$ ice-cold Tris- $\mathrm{HCl}$ buffer ( $\mathrm{pH}$ 7.4), centrifuged at $6000 \mathrm{rpm}$ for $10 \mathrm{~min}$ and the clear supernatant was stored at $-80{ }^{\circ} \mathrm{C}$ for biochemical assays.

\subsection{Oral Glucose Tolerance Test (OGTT)}

Blood samples were collected from the lateral tail vein of overnight fasted rats, which then received $3 \mathrm{~g} / \mathrm{kg}$ glucose solution orally. Other blood samples were collected at 30, 60, 90, and $120 \mathrm{~min}$ and glucose was measured using Spinreact (Girona, Spain) kit [24].

\subsection{Determination of Insulin, Glycated Hemoglobin (Hba1c) and Liver Function Markers}

Serum insulin and blood $\mathrm{HbA} 1 \mathrm{c} \%$ were assayed using RayBiotech (Peachtree Corners, GA, USA) and Biosystems (Barcelona, Spain) reagent kits. Alanine aminotransferase (ALT), aspartate aminotransferase (AST), lactate dehydrogenase (LDH), and alkaline phosphatase (ALP) were assayed in serum using Spinreact (Girona, Spain) kits.

\subsection{Determination of Liver Glycogen and Carbohydrate-Metabolizing Enzymes}

The content of glycogen [25], and activities of hexokinase [26], glucose-6-phosphatase (G-6-Pase) [27], fructose-1,6-biphosphatase (F-1,6-BPase) [28], and glycogen phosphorylase [29] were determined in the liver and the released inorganic phosphorus ( $\mathrm{Pi}$ ) was assayed according to Fiske and Subbarow [30] using Spinreact (Girona, Spain) assay kit.

\subsection{Determination of Oxidative Stress and Inflammation Markers, and HO-1 Activity}

ROS level was determined in the liver using $\mathrm{H}_{2}$ DCF-DA [31], and the LPO marker malondialdehyde (MDA) was determined as described by Ohkawa et al. [32]. GSH [33] and activities of SOD [34] and CAT [35] were assayed in the liver of rats. Hepatic TNF- $\alpha$, IL-6, and IL-1 $\beta$ were determined using R\&D Systems ((Minneapolis, MN, USA) kits and the activity of HO-1 was determined according to Abraham et al. [36]. In this assay, the samples were mixed with glucose-6-phosphate, hemin, nicotinamide adenine dinucleotide phosphate (NADPH), and glucose-6-phosphate dehydrogenase, incubated at $37^{\circ} \mathrm{C}$ for $1 \mathrm{~h}$, and the absorbance was measured at $464 \mathrm{~nm}$. 


\subsection{Histological and Immunohistochemical Examinations}

The samples were fixed in $10 \% \mathrm{NBF}$ for $24 \mathrm{~h}$, dehydrated, embedded in paraffin, and cut into $5-\mu \mathrm{m}$ thick sections, which were processed for staining with hematoxylin and eosin (H\&E) and Masson's trichrome (MT). Changes in the expression of Bcl-2, Bax, and caspase-3 were evaluated by immunohistochemistry (IHC). The sections were dewaxed, immersed in $0.05 \mathrm{M}$ citrate buffer ( $\mathrm{pH} 6.8$ ) for antigen retrieval and then treated with $0.3 \%$ hydrogen peroxide and protein block. After incubation with anti-Bcl-2 (Abcam, Cambridge, MA, USA, Cat. no. ab182858; dilution 1: 500), anti-Bax (ThermoFisher Scientific, Waltham, MA, USA, Cat. no. MA5-13-0300, 1: 100) or anti-caspase-3 (ThermoFisher Scientific, Waltham, MA, USA, Cat. no. PA5-77887, dilution 1/100), the sections were rinsed with PBS and then incubated with anti-rabbit secondary antibody (Cat\# K4003, EnVision $+{ }^{\mathrm{TM}}$ System HRP Labelled Polymer; Dako, Agilent, Santa Clara, CA, USA) for $30 \mathrm{~min}$ at room temperature. The slides were visualized with DAB kit and counter-stained with Mayer's hematoxylin. The prepared slides were examined using a Leica microscope adapted with Leica DFC camera (Leica Biosystems, Wetzlar, Germany).

\subsection{Gene Expression}

The effect of Gal on Nrf2, Keap1, and HO-1 mRNA in normal and diabetic rats was determined by qRT-PCR. Total RNA, isolated using TRIzol (ThermoFisher Scientific, Waltham, MA, USA), was purified, quantified using a nanodrop and samples with A260/A280 of $\geq 1.8$ were reverse transcribed into cDNA. Amplification of the cDNA was carried out using SYBR green master mix (ThermoFisher Scientific, Waltham, MA, USA) and the primers in Table 1 in a total reaction volume of $20 \mu \mathrm{L}$ on ABI 7500 real-time PCR System (Applied Biosystems, Waltham, MA, USA). The obtained results were analyzed using the $2^{-\Delta \Delta C t}$ method [37] and then normalized to $\beta$-actin.

Table 1. Primers used for qRT-PCR.

\begin{tabular}{|c|c|c|}
\hline Gene & Forward Primer Sequence $\left(5^{\prime}-3^{\prime}\right)$ & Reverse Primer Sequence $\left(5^{\prime}-3^{\prime}\right)$ \\
\hline Keap1 & TCAGCTAGAGGCGTACTGGA & TTCGGTTACCATCCTGCGAG \\
\hline$N r f 2$ & TTGTAGATGACCATGAGTCGC & TGTCCTGCTGTATGCTGCTT \\
\hline $\mathrm{HO}-1$ & GTAAATGCAGTGTTGGCCCC & ATGTGCCAGGCATCTCCTTC \\
\hline$A c t b$ & AGGAGTACGATGAGTCCGGC & CGCAGCTCAGTAACAGTCCG \\
\hline
\end{tabular}

\subsection{In Silico Molecular Docking Study}

The protein-drug interactions of Gal with Keap1 (PDB ID: 4L7B), NF-kB-DNA complex (PDB ID: 1LE9), and HO-1 (3HOK) were studied by in silico molecular docking analysis. The 3D structure of Gal was constructed by UCSF Chimera [38] and geometrically optimized at the B3LYP level of theory with the 6-311G $(\mathrm{d}, \mathrm{p})$ basis set using gaussian 09 software package. UCSF Chimera was employed for generating the .pdb structure of Gal and for stripping out all nonstandard residues [38]. AutoDock Vina and Autodock Tools (ADT) v1.5.6 packages were used for the docking study [39]. The drug and proteins were fully optimized for docking using ADT. These optimizations practicalities include removing water molecules, eliminating nonstandard amino acids residues, adding polar hydrogens, and adjusting the grid box configuration to the most functional active site. PyMOL v2.4 was employed for generating images and analyzing binding modes.

\subsection{Statistical Analysis}

The data are presented as the mean \pm standard error of the mean (SEM). Statistical differences among groups were estimated using one-way ANOVA followed by Tukey's post-hoc test on GraphPad Prism 7 (San Diego, CA, USA). A $p$ value $<0.05$ was considered statistically significant. 


\section{Results}

\subsection{Gal Ameliorates Hyperglycemia in Diabetic Rats}

The anti-hyperglycemic effect of Gal was evaluated through the assessment of OGTT, $\mathrm{HbA} 1 \mathrm{c} \%$, and insulin. Blood glucose was significantly elevated at all time points of the OGTT as revealed in Figure 1A and by the AUC analysis (Figure 1B; $p<0.001$ ). HbA1c\% showed a significant increase in the blood samples collected from diabetic rats (Figure 1C). In contrast, serum insulin was remarkably declined in STZ-induced diabetes $(p<0.001)$ as depicted in Figure 1D. Gal supplementation ameliorated blood glucose $(p<0.001)$ and $\mathrm{HbA1} \%(p<0.001)$ and increased insulin $(p<0.01)$ in diabetic rats. Notably, Gal did not affect blood glucose and insulin when supplemented to normal rats for six weeks.

A

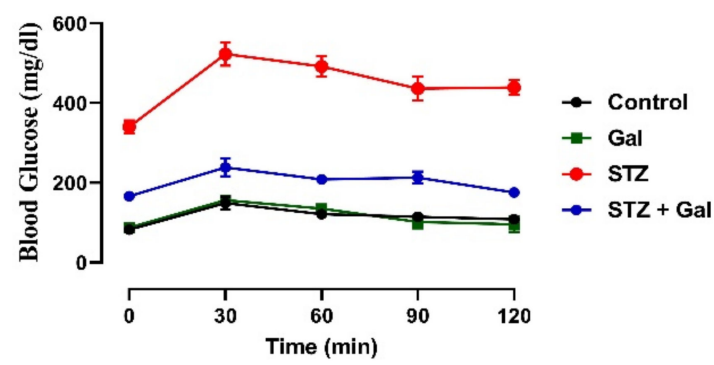

C

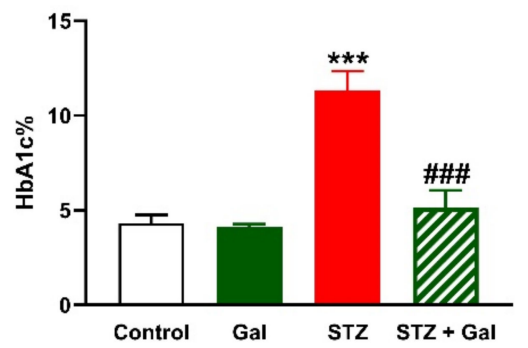

B

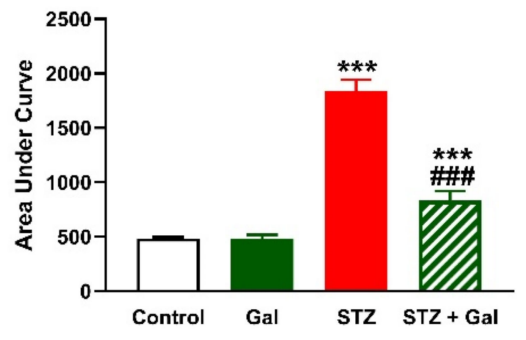

D

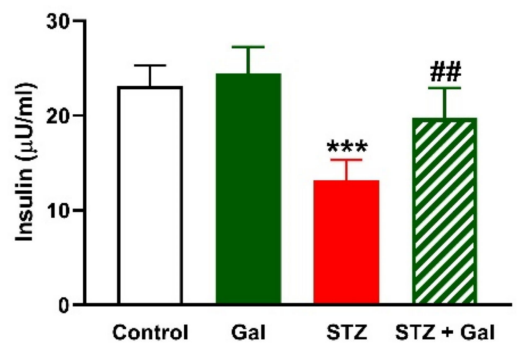

Figure 1. Galangin ameliorates hyperglycemia in diabetic rats. Galangin improved glucose tolerance $(\mathbf{A}, \mathbf{B})$, decreased $\mathrm{HbA1C} \%(\mathbf{C})$, and increased insulin (D) in diabetic rats. Data are mean $\pm \mathrm{SEM}, n=6$. *** $p<0.001$ versus control. ${ }^{\# \#} p<0.01$ and ${ }^{\# \#} p<0.001$ versus diabetic.

\subsection{Gal Alleviates Liver Glycogen and Carbohydrate Metabolizing Enzymes in Diabetic Rats}

Hepatic hexokinase activity (Figure 2A) was significantly reduced, whereas the activities of G-6-Pase (Figure 2B), F-1,6-BPase (Figure 2C), and glycogen phosphorylase (Figure 2D) were significantly upregulated $(p<0.001)$ in diabetic rats. Subsequently, hepatic glycogen was decreased $(p<0.001)$ in diabetic rats (Figure 2E). Gal suppressed G-6-Pase, F-1,6-BPase, and glycogen phosphorylase, and increased hexokinase activity and glycogen in diabetic rats, but had no effect in normal rats. 
A

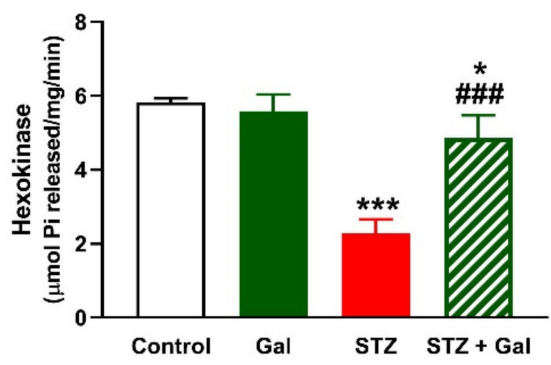

C

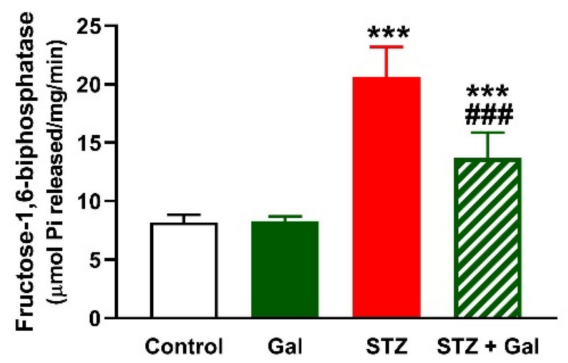

B

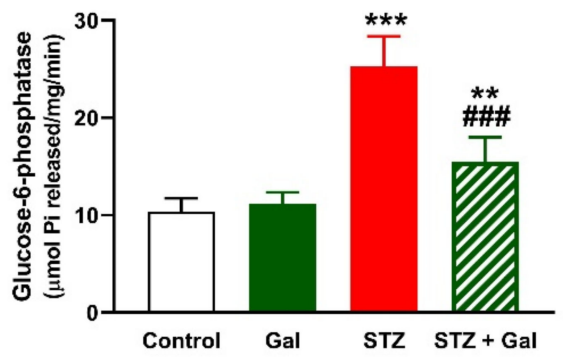

D

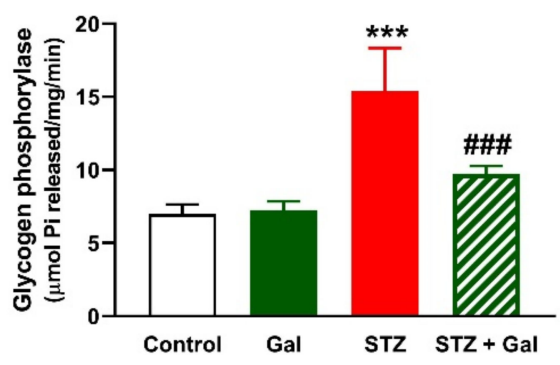

E

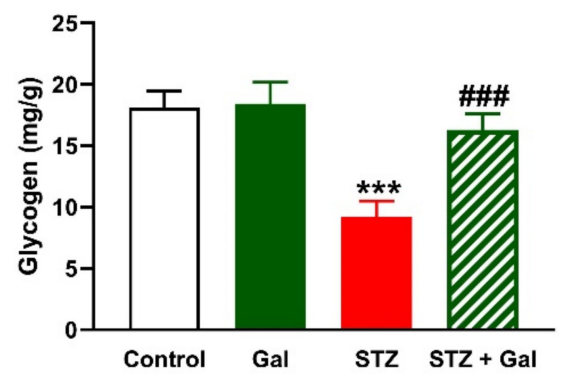

Figure 2. Galangin improves hepatic carbohydrate metabolism in diabetic rats. Galangin increased hepatic hexokinase activity (A), decreased glucose-6-Pase (B), fructose-1,6-BPase (C), and glycogen phosphorylase (D) and increased liver glycogen (E) in diabetic rats. Data are mean $\pm \mathrm{SEM}, n=6$. ${ }^{*} p<0.05,{ }^{* *} p<0.01$ and ${ }^{* * *} p<0.001$ versus control. ${ }^{\# \#} p<0.001$ versus diabetic.

\subsection{Gal Attenuates Liver Injury in Diabetic Rats}

Liver function markers in serum were determined and histopathological study was conducted to assess the protective effect of Gal on diabetes-associated liver injury. STZinduced rats exhibited remarkable increase $(p<0.001)$ in circulating ALT (Figure 3A), AST (Figure 3B), ALP (Figure 3C), and LDH (Figure 3D). Oral supplementation of Gal decreased these markers in the blood of diabetic animals without affecting their activities in normal rats. 
A

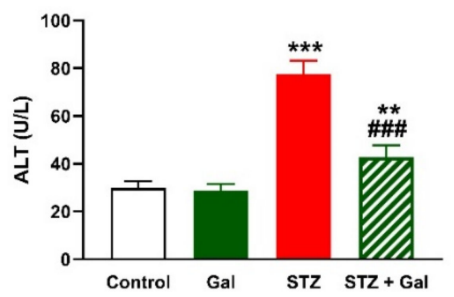

C

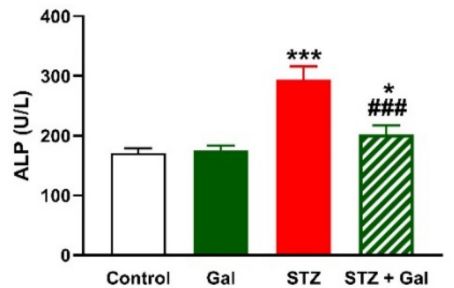

B

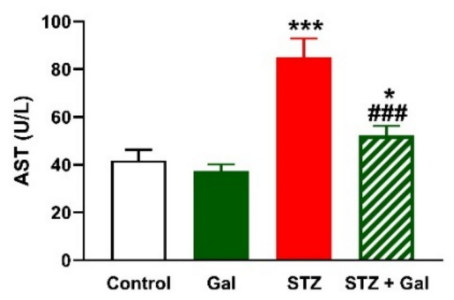

D

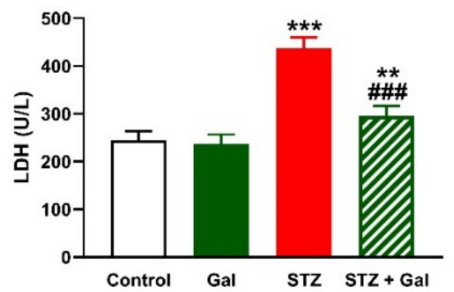

Figure 3. Galangin ameliorates circulating transaminases ALT (A), AST (B)), ALP (C), and LDH (D) in diabetic rats. Data are mean $\pm \mathrm{SEM}, n=6 .{ }^{*} p<0.05,{ }^{* *} p<0.01$ and ${ }^{* *} p<0.001$ versus control. \#\#\# $p<0.001$ versus diabetic.

Microscopically, control (Figure 4A) and Gal-supplemented rats (Figure 4B) revealed normal histological appearance with normal hepatocytes and central vein. In contrast, diabetic rats (Figure 4C) exhibited periportal apoptosis of the hepatic cells associated with fibroblastic cells proliferation. Diabetic rats that received Gal showed a mild degree of periportal apoptosis with scanty fibroblastic activity. Staining of the liver with MT revealed few collagen fibers around the portal area in the control (Figure 5A) and Gal-supplemented rats (Figure $5 \mathrm{~B})$, and significant increase $(p<0.001)$ in collagen and periportal fibrosis in diabetic rats (Figure $5 \mathrm{C}, \mathrm{E}$ ). Diabetic rats that received Gal showed marked decrease the periportal fibrosis $(p<0.001$; Figure $5 \mathrm{D}, \mathrm{E})$.
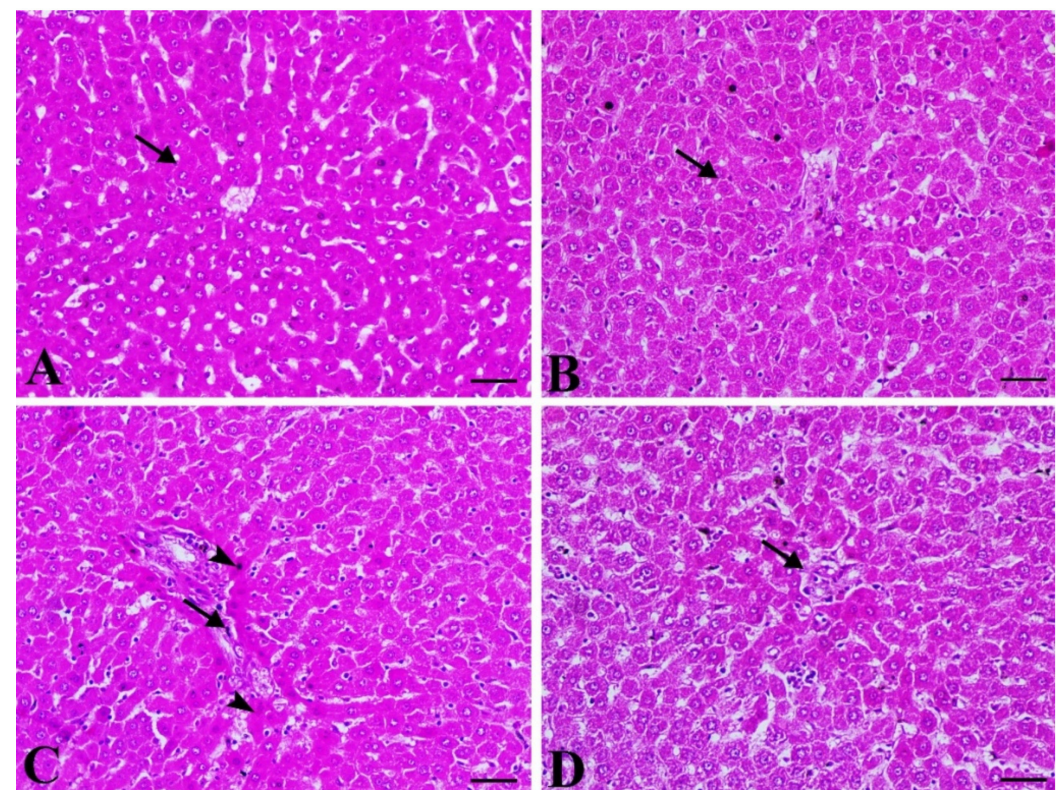

Figure 4. Photomicrographs of sections in the liver of (A) control rats showing normal hepatocytes and central vein (arrow), (B) galangin-supplemented rats showing normal hepatic tissues (arrow), (C) diabetic rats showing periportal apoptosis of the hepatic cells associated with fibroblastic cells proliferation (arrow), and (D) diabetic rats treated with galangin showing mild degree of periportal apoptosis with scanty fibroblastic activity (arrow). (H\&E, Scale bar $=50 \mu \mathrm{m}$ ). 


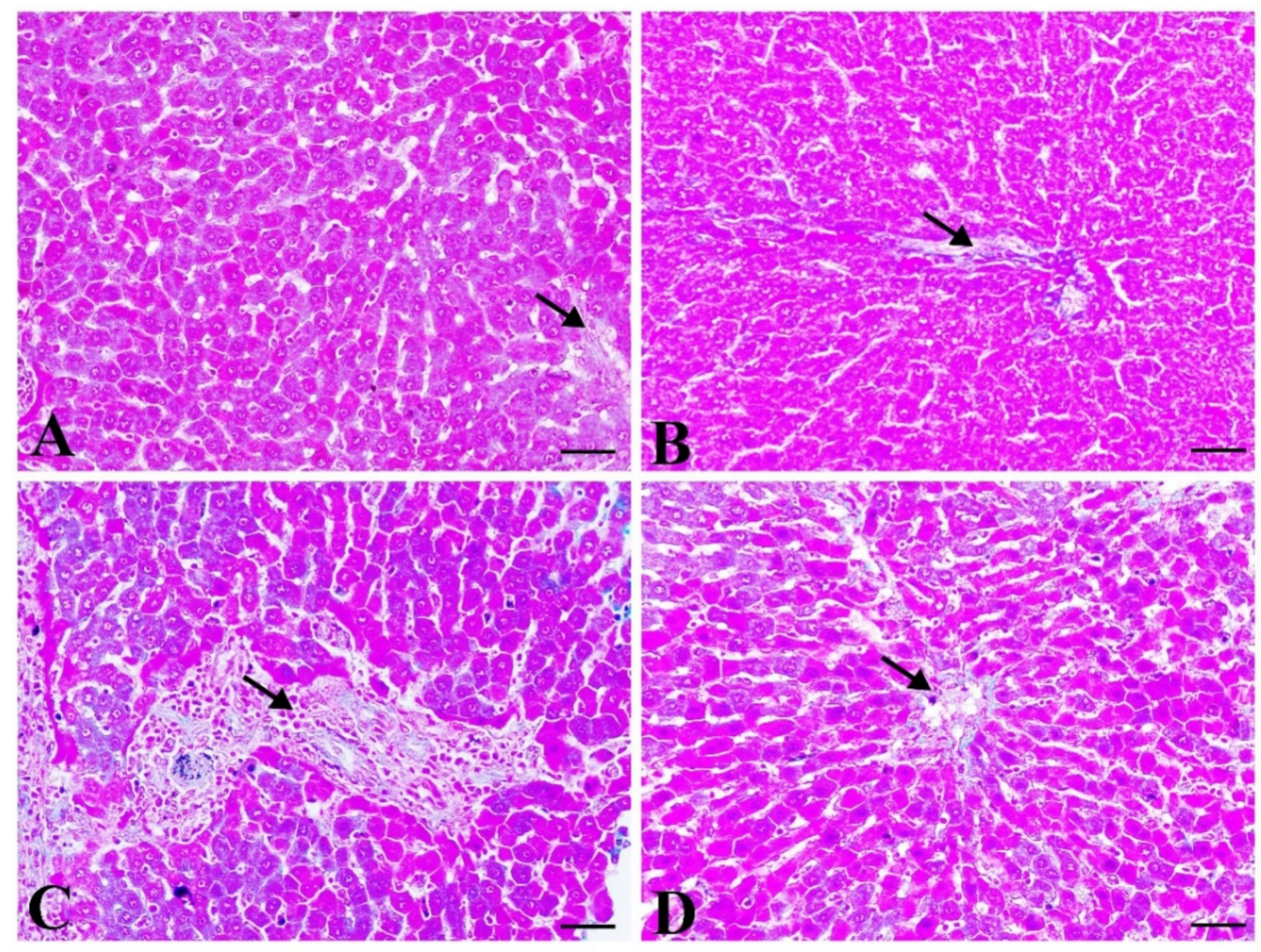

$\mathbf{E}$

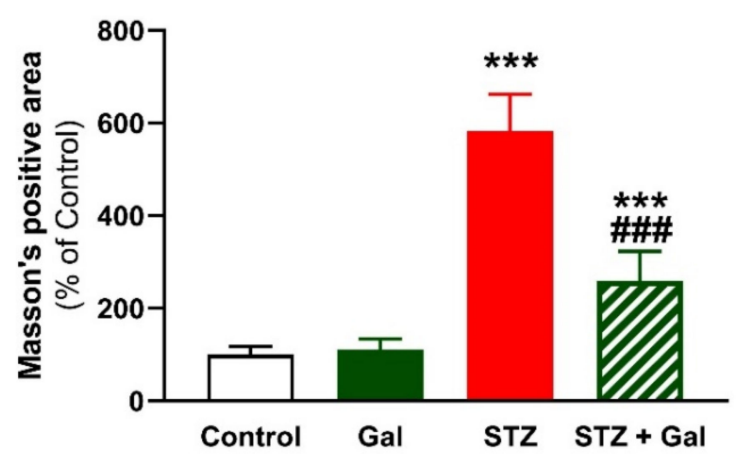

Figure 5. Photomicrographs of MT-stained sections in the liver of (A) control and (B) galanginsupplemented rats showing few collagen fibers around the portal area (arrow), (C) diabetic rats showing periportal fibrosis (arrow), and (D) diabetic rats treated with galangin showing marked decrease in collagen deposition. (Scale bar $=50 \mu \mathrm{m}$ ). (E) Image analysis showing significant increase in collagen deposition in diabetic rats and the ameliorative effect of galangin. Data are mean $\pm \mathrm{SEM}$, $n=6$. $^{* * *} p<0.001$ versus control and ${ }^{\# \#} p<0.001$ versus diabetic.

\subsection{Gal Attenuates Hepatic Oxidative Stress in Diabetic Rats}

Hepatic ROS (Figure 6A) and MDA (Figure 6B) were increased in diabetic rats when compared with the control rats $(p<0.001$ ). In contrast, hepatic GSH (Figure 6C), SOD (Figure 6D), and CAT (Figure 6E) were declined in diabetic rats $(p<0.001)$. While Gal had no effect on these markers in normal rats, it decreased ROS and LPO and boosted GSH, $\mathrm{SOD}$, and CAT in diabetic rats. 
A

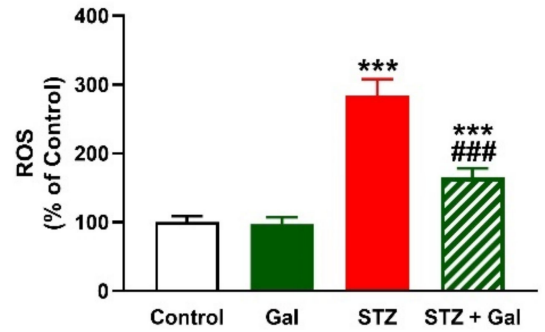

C

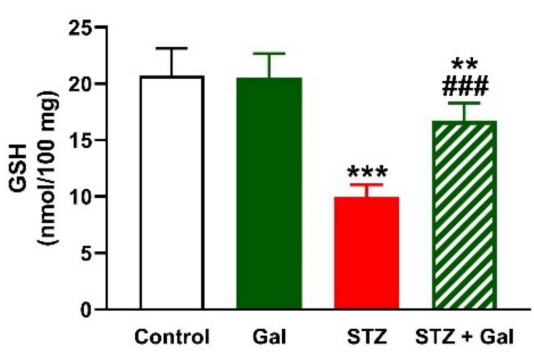

B

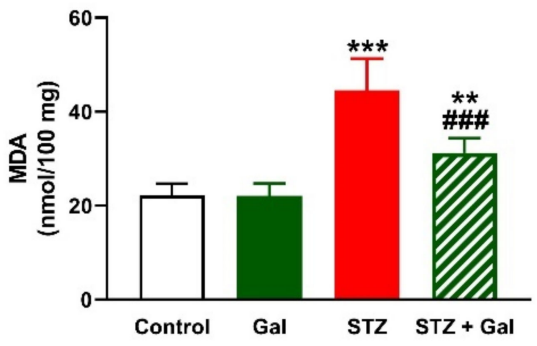

D

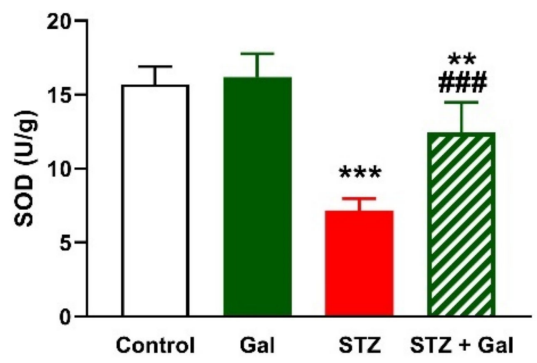

E

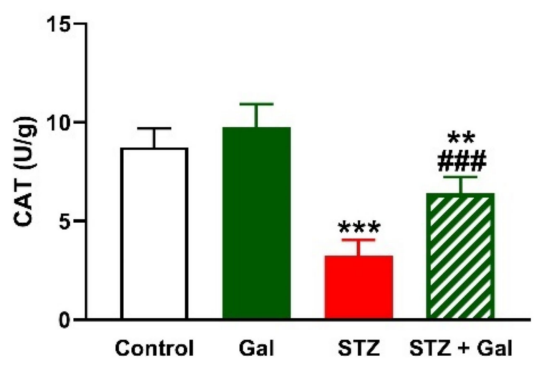

Figure 6. Galangin attenuates hepatic oxidative stress in diabetic rats. Galangin decreased hepatic ROS (A) and MDA (B), and increased GSH (C), SOD (D), and CAT (E) in diabetic rats. Data are mean $\pm \mathrm{SEM}, n=6$. $^{* *} p<0.01$ and ${ }^{* *} p<0.001$ versus control. ${ }^{* \# \#} p<0.001$ versus diabetic.

\subsection{Gal Mitigates Hepatic Inflammation in Diabetic Rats}

The anti-inflammatory effect of Gal was evaluated through measurement of hepatic TNF- $\alpha$, IL-1 $\beta$, and IL- 6 . In addition, we conducted a molecular docking simulation study to explore the possible interaction between Gal and NF- $\mathrm{kB}$. The results showed significant upregulation of hepatic TNF- $\alpha$, IL- $1 \beta$, and IL- 6 in diabetic rats $(p<0.001)$ as depicted in Figure 7A-C. Gal decreased these cytokines significantly $(p<0.001)$ in diabetic rats. 
A

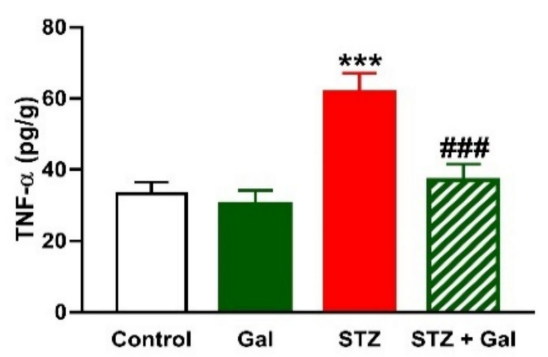

B

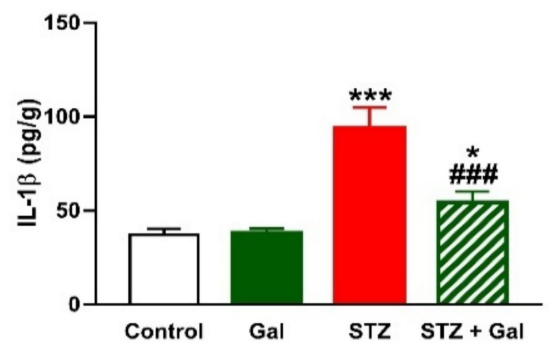

C

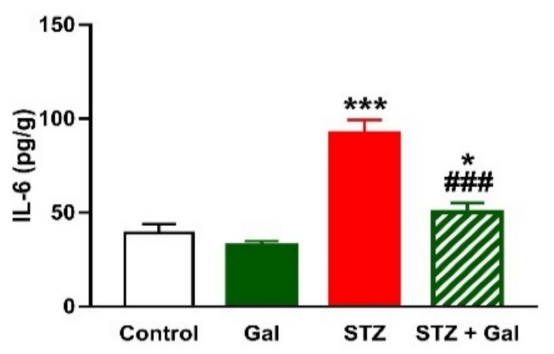

D
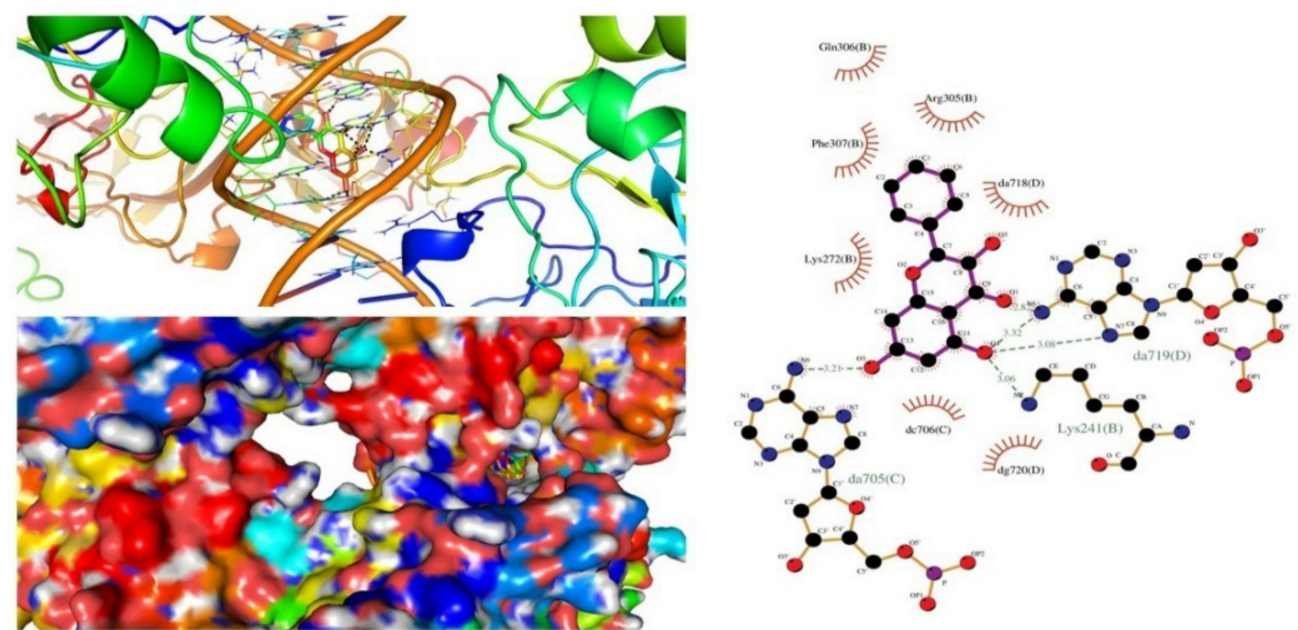

Figure 7. Galangin mitigates hepatic inflammation in diabetic rats. Galangin decreased hepatic TNF- $\alpha$ (A) IL-1 $\beta$ (B), and IL-6 (C) in diabetic rats. Data are mean \pm SEM, $n=6 .{ }^{*} p<0.05$ and ${ }^{* * *} p<0.001$ versus control. ${ }^{\# \#} p<0.001$ versus diabetic. (D) Molecular docking analysis revealing the binding between galangin and NF- $\mathrm{KB}$. Galangin docks into the binding site of NF- $\mathrm{kB}$ surrounded by the hydrophobic residues Lys272, Arg305, Gln306, and Phe307. A polar bond was detected between Gal and the residue Lys241.

The in-silico docking pattern for the interaction of Gal with NF-kBp50.p65 heterodimer is represented in Figure 7D. Gal was shown to dock onto the binding site of NF-kB surrounded by the hydrophobic residues Lys272, Arg305, Gln306, and Phe307. A polar bond was detected between Gal and the residue Lys241, which is involved in DNA binding. A strong binding of Gal to NF- $\mathrm{kB}$ was evaluated based on the scoring function value $(-9.5 \mathrm{kcal} / \mathrm{mol})$. 


\subsection{Gal Upregulates Nrf2/HO-1 Signaling in Liver of Diabetic Rats}

The mRNA abundance of Keap1, Nrf2, and HO-1 was determined to explore the effect of Gal on Nrf2/HO-1 signaling. Diabetes was associated with increased hepatic mRNA abundance of Keap1 (Figure 8A) and declined expression of Nrf2 (Figure 8B) and HO-1 (Figure 8C) $(p<0.001)$. Supplementation of Gal downregulated Keap1 and upregulated Nrf2 and HO-1 mRNA abundance in diabetic rats. Notably, Gal upregulated Nrf2 and HO-1 in normal rats $(p<0.05)$. These findings were supported by the results of HO-1, which was decreased in diabetic rats and increased in Gal-treated normal and diabetic rats.

To further explore the positive effect of Gal on Nrf2/HO-1 signaling, its binding ability with Keap1 and HO-1 was shown by molecular docking simulations. As shown in Figure 9A, Gal was shown to occupy the core cavity of Keap1, with the whole molecule sitting in the protein's central channel. An intensive inspection of Gal-Keap1 binding pocket showed various electrostatic interactions, including four polar bonds with residues Gly367 and Val606 and hydrophobic interactions with residues Leu365, Ala366, Arg415, Gly462, Gly464, Gly509, Ala510, Ala556, Ile559, and Gly603. A stable Gal-Keap1 complex was estimated based on the low binding energy obtained for this complex $(-9.1 \mathrm{kcal} / \mathrm{mol})$. After removing all nonstandard residues, the 3D structures of the co-crystal HO-1/QC-80 (PDB code $3 \mathrm{HOK}$ ) were used to investigate the binding pattern with Gal (Figure 9B). The estimated binding energy $(-7.5 \mathrm{kcal} / \mathrm{mol})$ indicates that $\mathrm{Gal}$ has a strong affinity towards HO-1. Four strong polar bonds were detected in the binding pocket of this complex with residues Ala94, Lys148, Phe169, and Ile172. A dense network of amino acid residues with a role in the hydrophobic interactions of this complex, including Ala94, Phe95, Gly98, Pro99, Leu141, Gly144, Gln145, Phe167, and Thr168 were detected.

A

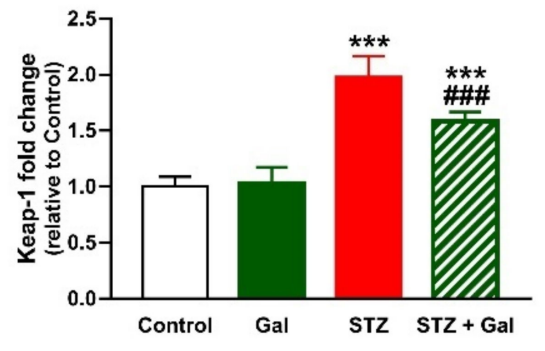

C

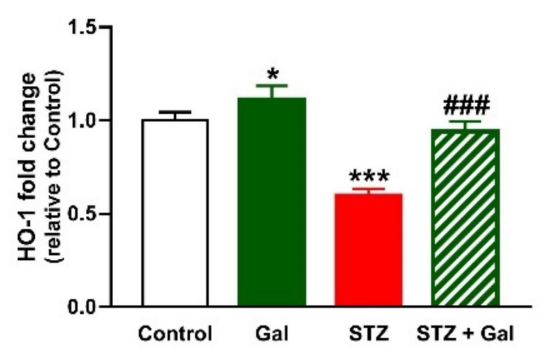

B

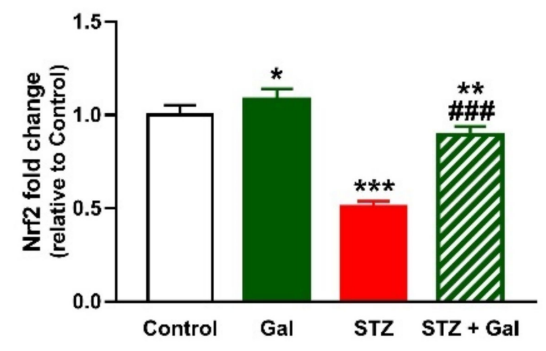

D

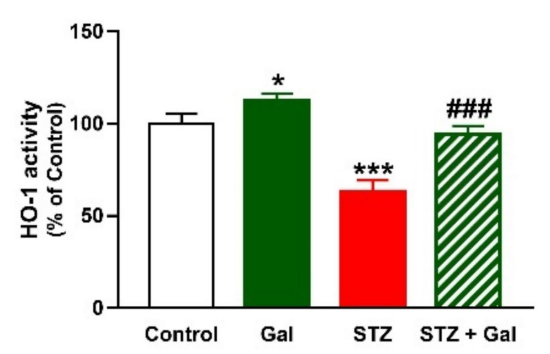

Figure 8. Galangin upregulates hepatic Nrf2/HO-1 pathway in diabetic rats. Galangin decreased hepatic Keap1 mRNA abundance in diabetic rats (A), and increased Nrf2 (B) and HO-1 (C) mRNA abundance, and HO-1 activity (D) in normal and diabetic rats. Data are mean \pm SEM, $n=6 .{ }^{*} p<0.05$, ${ }^{* *} p<0.01$ and ${ }^{* * *} p<0.001$ versus control. ${ }^{\# \#} p<0.001$ versus diabetic. 
A
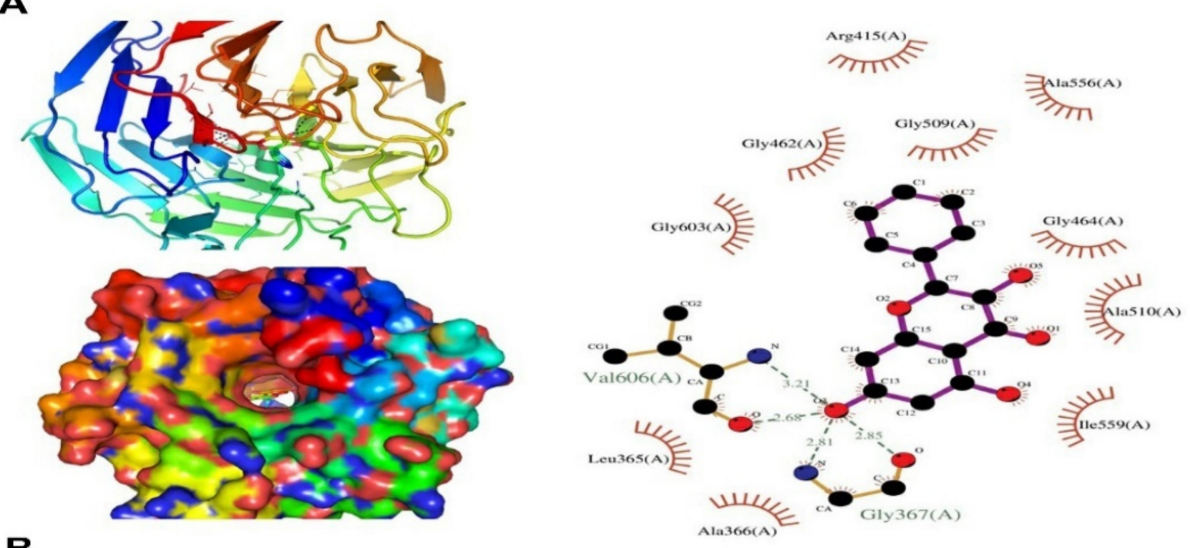

B
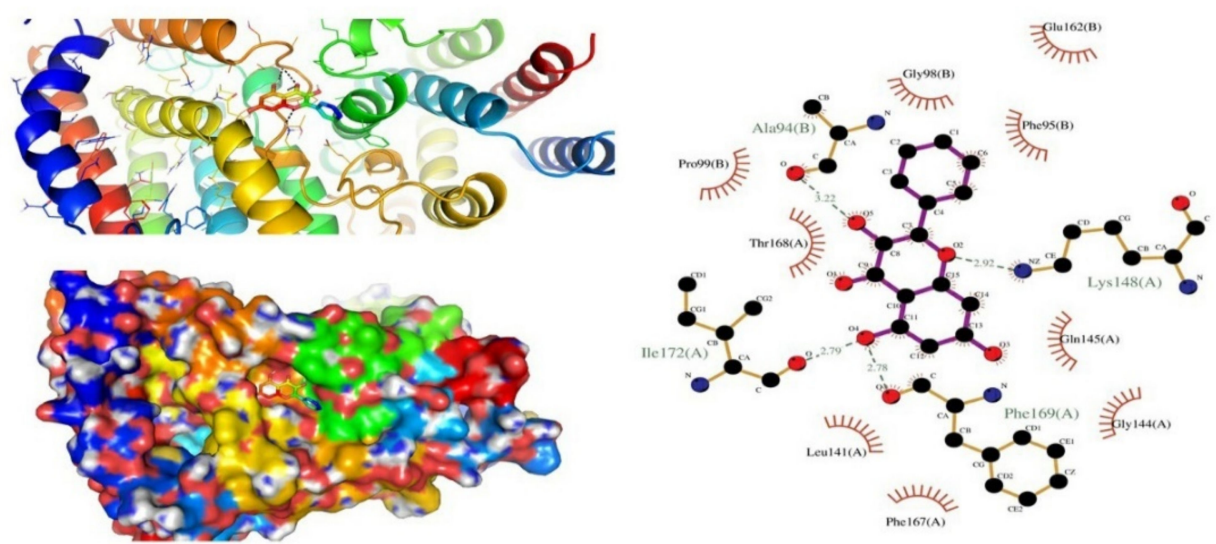

Figure 9. Molecular docking models of galangin with Keap1 and HO-1. (A) Galangin forms electrostatic interactions with Keap1, including four polar bonds with residues Gly367 and Val606, and hydrophobic interactions with residues Leu365, Ala366, Arg415, Gly462, Gly464, Gly509, Ala510, Ala556, Ile559, and Gly603. (B) Galangin forms four strong polar bonds with the residues Ala94, Lys148, Phe169, and Ile172, and hydrophobic interactions with the residues Ala94, Phe95, Gly98, Pro99, Leu141, Gly144, Gln145, Phe167, and Thr168 of HO-1.

\subsection{Gal Attenuates Apoptosis in Liver of Diabetic Rats}

Hepatic Bcl-2 was decreased (Figure 10A,B), and Bax (Figure 10A,C) and caspase-3 (Figure 10A-D) were increased in diabetic rats $(p<0.001)$. Gal upregulated hepatic Bcl-2 and downregulated Bax and caspase- 3 in diabetic rats $(p<0.001)$, whereas had no effect when supplemented to normal rats. 
A
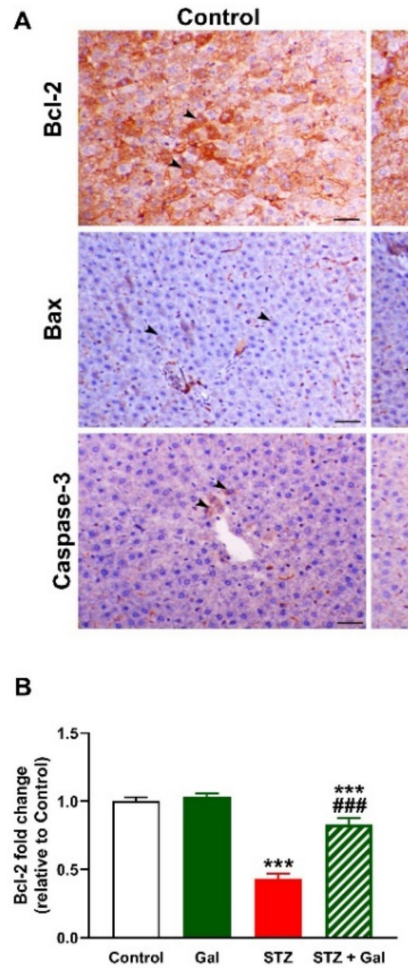

Gal

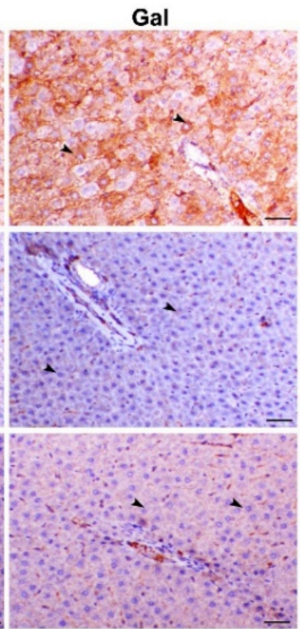

C

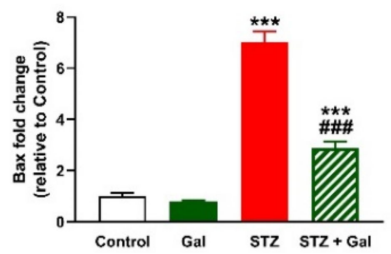

STZ
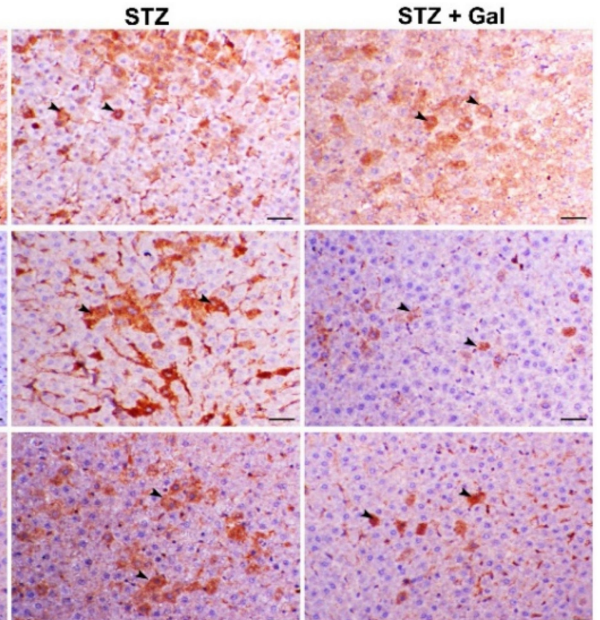

D

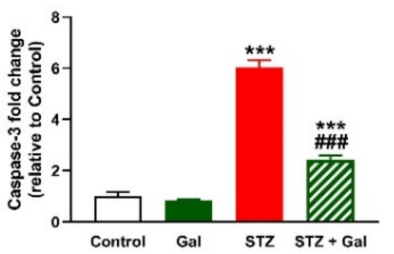

Figure 10. Galangin attenuates apoptosis in diabetic rats. (A) Photomicrographs of liver sections showing marked expression of Bcl-2 and mild expression of Bax and caspase- 3 in control and Gal-treated rats, marked decrease in Bcl-2 and increased Bax and caspase- 3 in diabetic rats, and ameliorated expression of all markers in diabetic rats treated with Gal (arrowheads) (Scale bar $=50 \mu \mathrm{m}$ ). (B-D) Gal increased Bcl-2 (B) and decreased Bax (C) and caspase-3 (D) in diabetic rats. Bax and caspase- 3 were determined by counting the positive cells per 1000 hepatocytes, while Bcl-2 positive staining was assessed using ImageJ (version 1.32j, NIH, Bethesda, MD, USA). The results are expressed as fold change relative to control. Data are mean $\pm \mathrm{SEM}, n=6$. ${ }^{* *} p<0.001$ versus control and ${ }^{\# \#} p<0.001$ versus diabetic.

\section{Discussion}

Hyperglycemia-mediated liver injury has been associated with increased ROS generation and an aberrant inflammatory response [3] and, therefore, diabetic patients have a high prevalence of liver disease [2,40]. This study investigated the protective effect of Gal, a flavonoid possesses antioxidant and anti-inflammatory effects in various disease models, including diabetes $[10,18,19,41]$, on liver injury in diabetic rats. We demonstrated that Gal attenuated oxidative stress, inflammatory response, and liver injury, and upregulated $\mathrm{Nrf2/HO}-1$ signaling in diabetic rats.

STZ-induced diabetes was employed to investigate the hepatoprotective effect of Gal. This model has been widely used for evaluating the in vivo anti-hyperglycemic potential of various agents $[22,23,42,43]$. STZ causes pancreatic $\beta$-cell death via ROS generation, DNA damage, PARP activation, and depletion of $\mathrm{NAD}^{+}$[44], explaining the observed reduction in serum insulin in this study. Besides hypoinsulinemia, rats that received STZ exhibited hyperglycemia manifested by elevated HbA1c and glucose intolerance. Sustained hyperglycemia can cause surplus generation of ROS leading to further destruction of the $\beta$-cells and worsening the glycemic status [45]. Treatment with Gal ameliorated hyperglycemia and glucose intolerance, and increased serum insulin. $\mathrm{HbA} 1 \mathrm{c} \%$ is of prominent value for effective diagnosis and management of chronic hyperglycemia and indicates good glycemic control at levels lower than 7\% [46]. Owing to its antioxidant efficacy, the anti-hyperglycemic effect of Gal could be attributed to protecting pancreatic $\beta$-cell against oxidative damage. In addition, in vitro studies using skeletal muscle cells demonstrated the DPP-4 inhibitory activity of Gal [21]. In vivo studies using fructose-supplemented rats 
showed the effectiveness of Gal to control hyperglycemia and upregulate insulin receptor gene expression [47].

Given the central role of the liver in maintaining glucose homeostasis, we assumed that the anti-hyperglycemic efficacy of Gal was associated its ability to modulate the carbohydrate metabolizing enzymes. Uncontrolled hepatic glycogenolysis and gluconeogenesis are central in hyperglycemia [48], and insulin deficiency decreases peripheral glucose utilization and increases hepatic glucose output, leading to hyperglycemia [48]. Although Gal has been reported to increase hexokinase and pyruvate kinase activities, and stimulate glycogen synthesis in HepG2 cells [49], its effect on carbohydrate metabolizing enzymes in the diabetic liver is unexplored. Here, hepatic glycogen content and hexokinase activity were declined, and glycogen phosphorylase, G-6-Pase, and F-1,6-BPase were upregulated in diabetic rats as previously reported $[50,51]$. The decrease in hexokinase activity occurs as a result of impaired insulin release and lead to suppressed glucose oxidation through glycolysis, whereas F-1,6-BPase dephosphorylates F-1,6-BP into F-6-P and G-6-Pase dephosphorylates glucose-6-phosphate into glucose, provoking gluconeogenesis [52,53]. Furthermore, hepatic glycogen phosphorylase activity has been increased in diabetic rats, leading to glycogenolysis and decreased glycogen content. Notably, Gal suppressed gluconeogenesis, improved hexokinase activity and glycogen synthesis, and downregulated G-6-Pase and F-1,6-BPase in diabetic rats. The effect of Gal on carbohydrate metabolizing enzymes is directly attributed to improved insulin release, which is known to promote glycogen synthase and suppress G-6-Pase and glycogen phosphorylase activities [54].

Besides its insulinotropic activity, the beneficial effect of Gal could be connected to the radical-scavenging and anti-inflammatory properties. Chronic hyperglycemia provokes excessive ROS production and inflammatory response, leading to liver injury $[1,55,56]$. Accordingly, liver injury in diabetic rats was observed in this study where liver function markers (ALT, AST, ALP, and LDH) were increased in the circulation along with multiple histopathological alterations, including periportal apoptosis of hepatocytes, fibroblastic cells proliferation, and periportal fibrosis. Excess deposition of collagen and fibrotic changes occur due to liver injury induced by chronic hyperglycemia-mediated oxidative stress and inflammation [57]. Here, the diabetic liver showed surplus ROS levels associated with increased LPO and declined GSH, SOD, and CAT. Hyperglycemia-mediated ROS can induce LPO, oxidative damage to DNA and proteins and cell death [58]. ROS can also activate NF- $\mathrm{kB}$ and increase the release of inflammatory mediators such as TNF- $\alpha$, IL- $1 \beta$, and IL-6, which were increased in the liver of diabetic rats in the present study. The implication of ROS in liver injury was supported by investigations showing the hepatoprotective activity of ROS scavengers [10,59]. Pro-inflammatory cytokines have a negative impact on glucose tolerance. For instance, TNF- $\alpha$ elicits hepatic glucose production and suppresses peripheral glucose uptake [60], and IL-1 $\beta$ provokes the loss of $\beta$-cell mass [61] and impairs insulin sensitivity in hepatocytes [62]. In addition, IL-6 impairs glucose tolerance and insulin signaling in hepatocytes $[63,64]$. Therefore, attenuation of inflammation and oxidative stress can protect against $\beta$-cell loss, hyperglycemia, glucose intolerance, and liver injury in diabetes. Gal ameliorated circulating ALT, AST, ALP, and LDH, and prevented hepatocellular damage in diabetic rats, demonstrating a hepatoprotective efficacy. In accordance, we have reported the efficacy of Gal against CP hepatotoxicity through suppression of oxidative stress, inflammatory response, and apoptosis [10]. Gal effectively reduced ROS, LPO, TNF- $\alpha$, IL- $1 \beta$, and IL- 6 , and enhanced cellular antioxidants in the diabetic liver. Consequently, Gal prevented apoptotic cell death in diabetic rats where it upregulated hepatic Bcl-2 and decreased Bax and caspase-3. Excess ROS can provoke apoptosis by activating Bax, which induces the loss of mitochondrial membrane potential [65]. Cytochrome $\mathrm{C}$ is then released into the cytosol and initiate the activation of caspase-3, which is the executioner enzyme that elicits DNA fragmentation and cell death [66]. In contrast, Bcl-2 suppresses the release of cytochrome $\mathrm{c}$ and prevent cellular death via apoptosis [67].

Next, we studied the possible involvement of Nrf2/HO-1 pathway in mediating the hepatoprotective activity of Gal in diabetic rats. Interestingly, Gal downregulated Keap-1 
and upregulated Nrf2 and HO-1 mRNA abundance and HO-1 activity in the liver of normal and diabetic rats. Upon activation, Nrf2 promotes the expression of many antioxidant and cytoprotective genes, including HO-1, SOD, and CAT $[8,68]$. The role of Nrf2 activation in protecting against oxidative liver injury, inflammation, and apoptosis has been adequately demonstrated [10-13]. Additionally, NRF2 ${ }^{-/}$mice are more vulnerable to hepatotoxicity than the wild-type mice [69], and knockout of Nrf2 increased hepatocyte injury induced by excessive iron accumulation [70]. Hence, activation of Nrf2 by Gal resulting in enhancement of antioxidant enzymes that neutralize excess ROS and prevent liver injury. Our previous research supports these findings where we demonstrated that Gal activates Nrf2/HO-1 pathway and prevents CP hepatotoxicity [10]. Besides attenuation of oxidative stress, Nrf2 activation might be involved in the anti-inflammatory activity of Gal. Nrf2 suppresses NF$\mathrm{kB}$ and pro-inflammatory mediators [71], and Gal downregulated NF- $\mathrm{BB}$ and inflammatory cytokines, and boosted IL-10 in LPS-stimulated microglia by activating Nrf2 [72]. Although the lack of Nrf2 and HO-1 protein expression data could be a limitation of this study, the results of $\mathrm{HO}-1$ activity confirmed the gene expression.

To figure out the binding modes of Gal with NF-kB, Keap1, and HO-1 at the molecular level, we conducted a molecular docking simulation study. Polar bonding, hydrophobic interactions, and drug conformation are the main factors contributing to the stability of biological macromolecules. Polar bonding is considered to be the main factor responsible for the binding of ligands into the active site of a specific protein. These interactions play crucial role in binding affinity, molecular recognition, and drug configuration in the binding pocket $[73,74]$. In addition, hydrophobic interactions take part in optimizing binding of drug lipophilic surface onto the hydrophobic regions of the protein binding cavity [75]. Therefore, a minimum energy ligand-protein interaction is essentially count on the geometrical coincidence of the ligand with protein's active site [75]. The results of docking analysis showed the compatibility of Gal with the active site of Keap1. The relatively low binding affinity $(-9.1 \mathrm{kcal} / \mathrm{mol})$ obtained for this complex suggests the activity of Gal as Keap1 inhibitor. In addition, the resting of Gal in the central cavity of Keap1 reflects the coincidence of the drug with the binding pocket. This coincidence could mediate the Nrf2 activation, which is in harmony with the previous published data [76]. Hence, Gal can interact with Keap1 and inhibit its binding with Nrf2 to assist transcriptional expression of the antioxidative genes. To investigate the key interactions of Gal with HO-1, we studied the binding pattern of Gal with the three-dimensional structure of HO-1 complexed with QC-80 (PDB 3HOK). The docking model of Gal with HO-1 was verified by redocking QC-80 with various previously published validated inhibitors using the same technique [77]. The results of this docking model manifest the good accommodation of Gal in the binding cavity of HO-1. Therefore, Gal is considered to have a high drug-likeness rating because it offers a comparatively stronger binding affinity than large number of recognized HO-1 inhibitors. The critical residues in the DNA active site of the NF-кBp50.p65 heterodimer, particularly Lys241 and Arg305, displayed strong electrostatic interactions with DNA [78]. Thus, reducing DNA binding interactions is possibly results in restraining NF-kB-dependent gene expression. The interaction of Gal with NF- $\kappa B-D N A$ complex suggests its ability to modulate NF- $\kappa B$ signaling. Inhibition of NF- $\kappa B$ binding to DNA is a possible mechanism involved in the modulatory effect of Gal. This notion is supported by the obtained interaction of Gal with several units of DNA.

\section{Conclusions}

The present results introduce new information on the protective efficacy of Gal against liver injury in diabetic rats. Gal ameliorated hyperglycemia, glucose tolerance, and hypoinsulinemia, and improved liver glycogen and carbohydrate metabolizing enzymes in diabetic rats. Treatment with Gal prevented histopathological alterations, ameliorated liver function markers, and suppressed ROS, LPO, pro-inflammatory cytokines and proapoptotic proteins in diabetic rats. In addition, Gal upregulated hepatic Nrf2/HO-1 pathway and boosted antioxidant defenses. Gal has the potential to bind to and modulate the 
activity NF-kB, Keap1, and HO-1 as revealed by molecular modeling simulations. Therefore, Gal possesses beneficial effects against oxidative stress and inflammation and can prevent liver injury in diabetes through amelioration of hyperglycemia and upregulation of Nrf2/HO-1 signaling. However, further studies to explore other mechanisms involved in its protective effects are needed.

Author Contributions: Conceptualization, A.M.M., M.H.A. and H.H.A.; methodology, A.M.M., M.H.A., W.A.-A., O.Y.A., A.F.A., M.A.A., H.H.A. and E.M.K.; software, A.M.M. and E.M.K.; validation, A.M.M. and M.H.A.; formal analysis, A.M.M., W.A.-A. and M.H.A.; investigation, W.A.-A., M.H.A., O.Y.A., A.F.A., E.M.K. and A.M.M.; resources, M.M.A., A.I.A., H.H.A. and A.M.M.; data curation, W.A.-A., A.M.M., M.H.A. and E.M.K.; writing—original draft preparation, A.M.M., O.Y.A. and E.M.K.; writing-review and editing, A.M.M.; visualization, A.M.M.; supervision, A.M.M.; project administration, H.H.A., M.H.A. and A.M.M.; funding acquisition, H.H.A. All authors have read and agreed to the published version of the manuscript.

Funding: This research was supported by Taif University Researchers Supporting Project number (TURSP-2020/29), Taif University, Taif, Saudi Arabia.

Institutional Review Board Statement: The experiment was conducted according to the guidelines of the National Institutes of Health (NIH publication No. 85-23, revised 2011) and was approved by Al-Hussein Bin Talal University animal care review committee (198/2019).

Informed Consent Statement: Not applicable.

Data Availability Statement: Data analyzed or generated during this study are included in this manuscript.

Acknowledgments: The current work was supported by Taif University Researchers Supporting Project number (TURSP-2020/29), Taif University, Taif, Saudi Arabia.

Conflicts of Interest: The authors declare no conflict of interest.

\section{References}

1. Levinthal, G.N.; Tavill, A.S. Liver Disease and Diabetes Mellitus. Clin. Diabetes 1999, 17, 73-81.

2. Harrison, S.A. Liver disease in patients with diabetes mellitus. J. Clin. Gastroenterol. 2006, 40, 68-76. [CrossRef] [PubMed]

3. Mohamed, J.; Nafizah, A.N.; Zariyantey, A.; Budin, S. Mechanisms of diabetes-induced liver damage: The role of oxidative stress and inflammation. Sultan Qaboos Univ. Med. J. 2016, 16, e132. [CrossRef]

4. Sharabi, K.; Tavares, C.D.; Rines, A.K.; Puigserver, P. Molecular pathophysiology of hepatic glucose production. Mol. Asp. Med. 2015, 46, 21-33. [CrossRef]

5. Petrović, A.; Bogojević, D.; Korać, A.; Golić, I.; Jovanović-Stojanov, S.; Martinović, V.; Ivanović-Matić, S.; Stevanović, J.; Poznanović, G.; Grigorov, I. Oxidative stress-dependent contribution of HMGB1 to the interplay between apoptosis and autophagy in diabetic rat liver. J. Physiol. Biochem. 2017, 73, 511-521. [CrossRef] [PubMed]

6. Nowotny, K.; Jung, T.; Höhn, A.; Weber, D.; Grune, T. Advanced glycation end products and oxidative stress in type 2 diabetes mellitus. Biomolecules 2015, 5, 194-222. [CrossRef]

7. De Lédinghen, V.; Vergniol, J.; Gonzalez, C.; Foucher, J.; Maury, E.; Chemineau, L.; Villars, S.; Gin, H.; Rigalleau, V. Screening for liver fibrosis by using FibroScan ${ }^{\circledR}$ and FibroTest in patients with diabetes. Dig. Liver Dis. 2012, 44, 413-418. [CrossRef]

8. Satta, S.; Mahmoud, A.M.; Wilkinson, F.L.; Alexander, M.Y.; White, S.J. The role of Nrf2 in cardiovascular function and disease. Oxid. Med. Cell. Longev. 2017, 2017, 9237263. [CrossRef] [PubMed]

9. Tang, W.; Jiang, Y.-F.; Ponnusamy, M.; Diallo, M. Role of Nrf2 in chronic liver disease. World J. Gastroenterol. WJG 2014, 20, 13079. [CrossRef]

10. Aladaileh, S.H.; Abukhalil, M.H.; Saghir, S.A.; Hanieh, H.; Alfwuaires, M.A.; Almaiman, A.A.; Bin-Jumah, M.; Mahmoud, A.M. Galangin activates Nrf2 signaling and attenuates oxidative damage, inflammation, and apoptosis in a rat model of cyclophosphamide-induced hepatotoxicity. Biomolecules 2019, 9, 346. [CrossRef]

11. Hassanein, E.H.M.; Sayed, A.M.; Hussein, O.E.; Mahmoud, A.M. Coumarins as Modulators of the Keap1/Nrf2/ARE Signaling Pathway. Oxid. Med. Cell. Longev. 2020, 2020, 1675957. [CrossRef] [PubMed]

12. Mahmoud, A.M.; Alexander, M.Y.; Tutar, Y.; Wilkinson, F.L.; Venditti, A. Oxidative Stress in Metabolic Disorders and DrugInduced Injury: The Potential Role of Nrf2 and PPARs Activators. Oxid. Med. Cell. Longev. 2017, 2017, 2508909. [CrossRef]

13. Hussein, O.E.; Hozayen, W.G.; Bin-Jumah, M.N.; Germoush, M.O.; El-Twab, S.M.A.; Mahmoud, A.M. Chicoric acid prevents methotrexate hepatotoxicity via attenuation of oxidative stress and inflammation and up-regulation of PPAR $\gamma$ and Nrf2/HO-1 signaling. Environ. Sci. Pollut. Res. Int. 2020, 27, 20725-20735. [CrossRef] 
14. Sugimoto, H.; Okada, K.; Shoda, J.; Warabi, E.; Ishige, K.; Ueda, T.; Taguchi, K.; Yanagawa, T.; Nakahara, A.; Hyodo, I. Deletion of nuclear factor-E2-related factor-2 leads to rapid onset and progression of nutritional steatohepatitis in mice. Am. J. Physiol.-Gastrointest. Liver Physiol. 2010, 298, G283-G294. [CrossRef]

15. Elsayed, R.H.; Kamel, E.M.; Mahmoud, A.M.; El-Bassuony, A.A.; Bin-Jumah, M.; Lamsabhi, A.M.; Ahmed, S.A. Rumex dentatus L. phenolics ameliorate hyperglycemia by modulating hepatic key enzymes of carbohydrate metabolism, oxidative stress and PPAR $\gamma$ in diabetic rats. Food Chem. Toxicol. 2020, 138, 111202. [CrossRef]

16. Germoush, M.O.; Elgebaly, H.A.; Hassan, S.; Kamel, E.M.; Bin-Jumah, M.; Mahmoud, A.M. Consumption of Terpenoids-Rich Padina pavonia Extract Attenuates Hyperglycemia, Insulin Resistance and Oxidative Stress, and Upregulates PPAR $\gamma$ in a Rat Model of Type 2 Diabetes. Antioxidants 2019, 9, 22. [CrossRef]

17. Aladaileh, S.; Al-Swailmi, F.; Abukhalil, M.; Shalayel, M. Galangin protects against oxidative damage and attenuates inflammation and apoptosis via modulation of NF-kB p65 and caspase-3 signaling molecules in a rat model of diabetic nephropathy. J. Physiol. Pharmacol. 2021, 72, 1. [CrossRef]

18. Abukhalil, M.H.; Althunibat, O.Y.; Aladaileh, S.H.; Al-Amarat, W.; Obeidat, H.M.; Alayn'Al-marddyah, A.; Hussein, O.E.; Alfwuaires, M.A.; Algefare, A.I.; Alanazi, K.M. Galangin attenuates diabetic cardiomyopathy through modulating oxidative stress, inflammation and apoptosis in rats. Biomed. Pharmacother. 2021, 138, 111410. [CrossRef] [PubMed]

19. Aloud, A.A.; Chinnadurai, V.; Govindasamy, C.; Alsaif, M.A.; Al-Numair, K.S. Galangin, a dietary flavonoid, ameliorates hyperglycaemia and lipid abnormalities in rats with streptozotocin-induced hyperglycaemia. Pharm. Biol. 2018, 56, 302-308. [CrossRef] [PubMed]

20. Aloud, A.A.; Veeramani, C.; Govindasamy, C.; Alsaif, M.A.; El Newehy, A.S.; Al-Numair, K.S. Galangin, a dietary flavonoid, improves antioxidant status and reduces hyperglycemia-mediated oxidative stress in streptozotocin-induced diabetic rats. Redox Rep. 2017, 22, 290-300. [CrossRef]

21. Kalhotra, P.; Chittepu, V.C.; Osorio-Revilla, G.; Gallardo-Velázquez, T. Discovery of galangin as a potential DPP-4 inhibitor that improves insulin-stimulated skeletal muscle glucose uptake: A combinational therapy for diabetes. Int. J. Mol. Sci. 2019, 20, 1228. [CrossRef]

22. Al Hroob, M.A.; Abukhalil, M.H.; Alghonmeen, R.D.; Mahmoud, A.M. Ginger alleviates hyperglycemia-induced oxidative stress, inflammation and apoptosis and protects rats against diabetic nephropathy. Biomed. Pharmacother. 2018, 106, 381-389. [CrossRef] [PubMed]

23. Althunibat, O.Y.; Hroob, A.M.A.; Abukhalil, M.H.; Germoush, M.O.; Bin-Jumah, M.; Mahmoud, A.M. Fisetin ameliorates oxidative stress, inflammation and apoptosis in diabetic cardiomyopathy. Life Sci. 2019, 221, 83-92. [CrossRef] [PubMed]

24. Trinder, P. Determination of Glucose in Blood Using Glucose Oxidase with an Alternative Oxygen Acceptor. Ann. Clin. Biochem. Int. J. Biochem. Lab. Med. 1969, 6, 24-27. [CrossRef]

25. Seifter, S.; Dayton, S. The estimation of glycogen with the anthrone reagent. Arch. Biochem. 1950, 25, 191-200.

26. Brandstrup, N.; Kirk, J.E.; Bruni, C. The hexokinase and phosphoglucoisomerase activities of aortic and pulmonary artery tissue in individuals of various ages. J. Gerontol. 1957, 12, 166-171. [CrossRef] [PubMed]

27. Koide, H.; Oda, T. Pathological occurrence of glucose-6-phosphatase in serum in liver diseases. Clin. Chim. Acta 1959, 4, 554-561. [CrossRef]

28. Freedland, R.A.; Harper, A.E. Metabolic adaptations in higher animals. V. The study of metabolic pathways by means of metabolic adaptations. J. Biol. Chem. 1959, 234, 1350-1354. [CrossRef]

29. Stalmans, W.; Hers, H.G. The stimulation of liver phosphorylase b by AMP, fluoride and sulfate. A technical note on the specific determination of the $\mathrm{a}$ and $\mathrm{b}$ forms of liver glycogen phosphorylase. Eur. J. Biochem. 1975, 54, 341-350. [CrossRef]

30. Fiske, C.; Subbarow, Y. The colourimetric determination of phosphorus. J. Biol. Chem. 1925, 66, 375-400. [CrossRef]

31. Hozayen, W.G.; Mahmoud, A.M.; Desouky, E.M.; El-Nahass, E.-S.; Soliman, H.A.; Farghali, A.A. Cardiac and pulmonary toxicity of mesoporous silica nanoparticles is associated with excessive ROS production and redox imbalance in Wistar rats. Biomed. Pharmacother. 2019, 109, 2527-2538. [CrossRef]

32. Ohkawa, H.; Ohishi, N.; Yagi, K. Assay for lipid peroxides in animal tissues by thiobarbituric acid reaction. Anal. Biochem. 1979, 95, 351-358. [CrossRef]

33. Griffith, O.W.J.A.b. Determination of glutathione and glutathione disulfide using glutathione reductase and 2-vinylpyridine. Anal. Biochem. 1980, 106, 207-212. [CrossRef]

34. Marklund, S.; Marklund, G. Involvement of the Superoxide Anion Radical in the Autoxidation of Pyrogallol and a Convenient Assay for Superoxide Dismutase. FEBS Eur. J. Biochem. 1974, 47, 469-474. [CrossRef] [PubMed]

35. Cohen, G.; Dembiec, D.; Marcus, J. Measurement of catalase activity in tissue extracts. Anal. Biochem. 1970, 34, 30-38. [CrossRef]

36. Abraham, N.; Lutton, J.; Levere, R.J. Heme metabolism and erythropoiesis in abnormal iron states: Role of delta-aminolevulinic acid synthase and heme oxygenase. Exp. Hematol. 1985, 13, 838. [PubMed]

37. Livak, K.J.; Schmittgen, T.D. Analysis of relative gene expression data using real-time quantitative PCR and the $2-\Delta \Delta C T$ method. Methods 2001, 25, 402-408. [CrossRef]

38. Pettersen, E.F.; Goddard, T.D.; Huang, C.C.; Couch, G.S.; Greenblatt, D.M.; Meng, E.C.; Ferrin, T.E. UCSF Chimera-A visualization system for exploratory research and analysis. J. Comput. Chem. 2004, 25, 1605-1612. [CrossRef]

39. Trott, O.; Olson, A.J. AutoDock Vina: Improving the speed and accuracy of docking with a new scoring function, efficient optimization, and multithreading. J. Comput. Chem. 2010, 31, 455-461. [CrossRef] 
40. Tolman, K.G.; Fonseca, V.; Dalpiaz, A.; Tan, M.H. Spectrum of liver disease in type 2 diabetes and management of patients with diabetes and liver disease. Diabetes Care 2007, 30, 734-743. [CrossRef]

41. Kim, M.E.; Park, P.R.; Na, J.Y.; Jung, I.; Cho, J.H.; Lee, J.S. Anti-neuroinflammatory effects of galangin in LPS-stimulated BV-2 microglia through regulation of IL-1 $\beta$ production and the NF-KB signaling pathways. Mol. Cell. Biochem. 2019, 451, 145-153. [CrossRef] [PubMed]

42. Al-Rasheed, N.M.; Al-Rasheed, N.M.; Hasan, I.H.; Al-Amin, M.A.; Al-Ajmi, H.N.; Mohamad, R.A.; Mahmoud, A.M. Simvastatin ameliorates diabetic cardiomyopathy by attenuating oxidative stress and inflammation in rats. Oxid. Med. Cell. Longev. 2017, 2017, 1092015. [CrossRef]

43. Al-Rasheed, N.M.; Al-Rasheed, N.M.; Hasan, I.H.; Al-Amin, M.A.; Al-Ajmi, H.N.; Mahmoud, A.M. Sitagliptin attenuates cardiomyopathy by modulating the JAK/STAT signaling pathway in experimental diabetic rats. Drug Des. Devel. Ther. 2016, 10, 2095-2107. [CrossRef]

44. Szkudelski, T. The mechanism of alloxan and streptozotocin action in B cells of the rat pancreas. Physiol. Res. 2001, 50, 537-546. [PubMed]

45. Lenzen, S.; Drinkgern, J.; Tiedge, M. Low antioxidant enzyme gene expression in pancreatic islets compared with various other mouse tissues. Free Radic. Biol. Med. 1996, 20, 463-466. [CrossRef]

46. American Diabetes Association. Standards of medical care in diabetes-2014. Diabetes Care 2014, 36, S11-S66. [CrossRef]

47. Sivakumar, A.S.; Viswanathan, P.; Anuradha, C.V. Dose-dependent effect of galangin on fructose-mediated insulin resistance and oxidative events in rat kidney. Redox Rep. 2010, 15, 224-232. [CrossRef]

48. Nordlie, R.C.; Foster, J.D.; Lange, A.J. Regulation of glucose production by the liver. Annu. Rev. Nutr. 1999, 19, 379-406. [CrossRef]

49. Liu, Y.; Liang, X.; Zhang, G.; Kong, L.; Peng, W.; Zhang, H. Galangin and pinocembrin from propolis ameliorate insulin resistance in HepG2 cells via regulating Akt/mTOR signaling. Evid.-Based Complement. Altern. Med. 2018, 2018, 7971842. [CrossRef]

50. Prince, P.S.M.; Kamalakkannan, N. Rutin improves glucose homeostasis in streptozotocin diabetic tissues by altering glycolytic and gluconeogenic enzymes. J. Biochem. Mol. Toxicol. 2006, 20, 96-102. [CrossRef]

51. Babujanarthanam, R.; Kavitha, P.; Pandian, M.R. Quercitrin, a bioflavonoid improves glucose homeostasis in streptozotocininduced diabetic tissues by altering glycolytic and gluconeogenic enzymes. Fundam. Clin. Pharmacol. 2010, 24, 357-364. [CrossRef] [PubMed]

52. Pilkis, S.J.; Claus, T.H. Hepatic gluconeogenesis/glycolysis: Regulation and structure/function relationships of substrate cycle enzymes. Annu. Rev. Nutr. 1991, 11, 465-515. [CrossRef] [PubMed]

53. Roden, M.; Bernroider, E. Hepatic glucose metabolism in humans-its role in health and disease. Best Pract. Res. Clin. Endocrinol. Metab. 2003, 17, 365-383. [CrossRef]

54. Golden, S.; Wals, P.A.; Okajima, F.; Katz, J. Glycogen synthesis by hepatocytes from diabetic rats. Biochem. J. 1979, 182, 727-734. [CrossRef]

55. Mahmoud, A.M.; Ashour, M.B.; Abdel-Moneim, A.; Ahmed, O.M. Hesperidin and naringin attenuate hyperglycemia-mediated oxidative stress and proinflammatory cytokine production in high fat fed/streptozotocin-induced type 2 diabetic rats. J. Diabetes Complicat. 2012, 26, 483-490. [CrossRef] [PubMed]

56. Jellinger, P.S. Metabolic consequences of hyperglycemia and insulin resistance. Clin. Cornerstone 2007, 8, S30-S42. [CrossRef]

57. Bataller, R.; Brenner, D.A. Liver fibrosis. J. Clin. Investig. 2005, 115, 209-218. [CrossRef] [PubMed]

58. Tiwari, B.K.; Pandey, K.B.; Abidi, A.B.; Rizvi, S.I. Markers of Oxidative Stress during Diabetes Mellitus. J. Biomark. 2013, 2013, 378790. [CrossRef]

59. Ranneh, Y.; Akim, A.M.; Hamid, H.A.; Khazaai, H.; Fadel, A.; Mahmoud, A.M. Stingless bee honey protects against lipopolysaccharide induced-chronic subclinical systemic inflammation and oxidative stress by modulating Nrf2, NF- $\mathrm{kB}$ and p38 MAPK. Nutr. Metab. 2019, 16, 15. [CrossRef]

60. Lang, C.H.; Dobrescu, C.; Bagby, G.J. Tumor necrosis factor impairs insulin action on peripheral glucose disposal and hepatic glucose output. Endocrinology 1992, 130, 43-52. [CrossRef]

61. Dinarello, C.A.; Donath, M.Y.; Mandrup-Poulsen, T. Role of IL-1beta in type 2 diabetes. Curr. Opin. Endocrinol. Diabetes Obes. 2010, 17, 314-321. [CrossRef] [PubMed]

62. Nov, O.; Kohl, A.; Lewis, E.C.; Bashan, N.; Dvir, I.; Ben-Shlomo, S.; Fishman, S.; Wueest, S.; Konrad, D.; Rudich, A. Interleukin1beta may mediate insulin resistance in liver-derived cells in response to adipocyte inflammation. Endocrinology 2010, 151, 4247-4256. [CrossRef] [PubMed]

63. Senn, J.J.; Klover, P.J.; Nowak, I.A.; Mooney, R.A. Interleukin-6 induces cellular insulin resistance in hepatocytes. Diabetes 2002, 51, 3391-3399. [CrossRef] [PubMed]

64. Müller, S.; Martin, S.; Koenig, W.; Hanifi-Moghaddam, P.; Rathmann, W.; Haastert, B.; Giani, G.; Illig, T.; Thorand, B.; Kolb, H. Impaired glucose tolerance is associated with increased serum concentrations of interleukin 6 and co-regulated acute-phase proteins but not TNF-alpha or its receptors. Diabetologia 2002, 45, 805-812. [CrossRef]

65. Shi, Y.; Chen, J.; Weng, C.; Chen, R.; Zheng, Y.; Chen, Q.; Tang, H. Identification of the protein-protein contact site and interaction mode of human VDAC1 with Bcl-2 family proteins. Biochem. Biophys. Res. Commun. 2003, 305, 989-996. [CrossRef]

66. Redza-Dutordoir, M.; Averill-Bates, D.A. Activation of apoptosis signalling pathways by reactive oxygen species. Biochim. Biophys. Acta-Mol. Cell Res. 2016, 1863, 2977-2992. [CrossRef] [PubMed] 
67. Herrera, B.; Fernández, M.; Alvarez, A.M.; Roncero, C.; Benito, M.; Gil, J.; Fabregat, I. Activation of caspases occurs downstream from radical oxygen species production, Bcl-xL down-regulation, and early cytochrome $\mathrm{C}$ release in apoptosis induced by transforming growth factor $\beta$ in rat fetal hepatocytes. Hepatology 2001, 34, 548-556. [CrossRef]

68. Baird, L.; Yamamoto, M.J.M.; Biology, C. The Molecular Mechanisms Regulating the KEAP1-NRF2 Pathway. Mol. Cell. Biol. 2020, 40, 40. [CrossRef]

69. Liu, J.; Wu, K.C.; Lu, Y.F.; Ekuase, E.; Klaassen, C.D. Nrf2 protection against liver injury produced by various hepatotoxicants. Oxid. Med. Cell Longev. 2013, 2013, 305861. [CrossRef] [PubMed]

70. Silva-Gomes, S.; Santos, A.G.; Caldas, C.; Silva, C.M.; Neves, J.V.; Lopes, J.; Carneiro, F.; Rodrigues, P.N.; Duarte, T.L. Transcription factor NRF2 protects mice against dietary iron-induced liver injury by preventing hepatocytic cell death. J. Hepatol. 2014, 60, 354-361. [CrossRef]

71. Wardyn, J.D.; Ponsford, A.H.; Sanderson, C.M. Dissecting molecular cross-talk between Nrf2 and NF-kB response pathways. Biochem. Soc. Trans. 2015, 43, 621-626. [CrossRef]

72. Choi, M.-J.; Lee, E.-J.; Park, J.-S.; Kim, S.-N.; Park, E.-M.; Kim, H.-S. Anti-inflammatory mechanism of galangin in lipopolysaccharide-stimulated microglia: Critical role of PPAR- $\gamma$ signaling pathway. Biochem. Pharmacol. 2017, 144, 120-131. [CrossRef] [PubMed]

73. Abukhalil, M.H.; Hussein, O.E.; Bin-Jumah, M.; Saghir, S.A.; Germoush, M.O.; Elgebaly, H.A.; Mosa, N.M.; Hamad, I.; Qarmush, M.M.; Hassanein, E.M.; et al. Farnesol attenuates oxidative stress and liver injury and modulates fatty acid synthase and acetyl-CoA carboxylase in high cholesterol-fed rats. Environ. Sci. Pollut. Res. 2020, 27, 30118-30132. [CrossRef] [PubMed]

74. Kamel, E.M.; Lamsabhi, A.M.J.O.; Chemistry, B. The quasi-irreversible inactivation of cytochrome P450 enzymes by paroxetine: A computational approach. Org. Biomol. Chem. 2020, 18, 3334-3345. [CrossRef]

75. Kubinyi, H. Hydrogen bonding: The last mystery in drug design. In Pharmacokinetic Optimization in Drug Research: Biological, Physicochemical, and Computational Strategies; John Wiley \& Sons: Zürich, Switzerland, 2001; pp. 513-524.

76. Liu, Q.; Hu, Y.; Cao, Y.; Song, G.; Liu, Z.; Liu, X. Chicoric acid ameliorates lipopolysaccharide-induced oxidative stress via promoting the Keap1/Nrf2 transcriptional signaling pathway in BV-2 microglial cells and mouse brain. J. Agric. Food Chem. 2017, 65, 338-347. [CrossRef]

77. Salerno, L.; Amata, E.; Romeo, G.; Marrazzo, A.; Prezzavento, O.; Floresta, G.; Sorrenti, V.; Barbagallo, I.; Rescifina, A.; Pittalà, V.J. Potholing of the hydrophobic heme oxygenase-1 western region for the search of potent and selective imidazole-based inhibitors. Eur. J. Med. Chem. 2018, 148, 54-62. [CrossRef] [PubMed]

78. Gobec, M.; Tomašič, T.; Markovič, T.; Mlinarič-Raščan, I.; Dolenc, M.S.; Jakopin, Ž. Antioxidant and anti-inflammatory properties of 1, 2, 4-oxadiazole analogs of resveratrol. Chem.-Biol. Interact. 2015, 240, 200-207. [CrossRef] [PubMed] 